\title{
Winter Diets of Mule Deer in Relation to Bit- terbrush Abundance
}

\author{
GALEN C. BURRELL
}

\begin{abstract}
During the winters of 1974-1975 and 1975-1976 food habits of the Entiat mule deer (Odocoileus hemionus hemionus) herd were quantified in sites with high, medium and low antelope bitterbrush (Purshia tridentata) abundance. Using a microscopic technique, 27 plant species were identified in fecal samples. Bitterbrush, buckwheat (Eriogonum spp.), arrowleaf balsamroot (Balsamorhiza sagittata) and lupine (Lupinus spp.) combined made up 87\%-93\% of the diet in the three sites. Bitterbrush use was heavy in sites where it was available; however, as its availability declined, buckwheat replaced it in the herd's diet. In the site with a low bitterbrush abundance lupine also replaced bitterbrush in the herd's diet. Balsamroot use remained relatively constant in all sites during both winters. Changes in bitterbrush abundance significantly affected the diet of the mule deer herd; however, these changes were net thought to adversely affect the winter survival of the deer herd.
\end{abstract}

Antelope bitterbrush (Purshia tridentata) is the most abundant shrub found in the Entiat mule deer (Odocoileus hemionus hemionus) herd's winter range, located in eastern Washington. Within the Entiat winter range a reduction in the amount of available bitterbrush has occurred due to fire, decadence, and lack of regeneration (Davis et al. 1970). This reduction in bitterbrush abundance has been thought to be a factor in the decline of the Entiat mule deer herd (Gjertson 1973) though no food habits studies have been conducted. The purpose of this study was to quantify the effect of bitterbrush abundance on the winter diet of the Entiat mule deer herd by examining the food habits of deer in sites with high, medium, and low bitterbrush abundance.

In other areas where bitterbrush occurs it has been found to be heavily eaten by mule deer in fall and winter (Cliff 1939, Edwards 1942, Hoskins and Dalke 1955, Leach 1956, Wilkins 1957, Richens 1967). Heavy use has been correlated with a high nutrient content of bitterbrush leaders (Smith and Gaufin 1950, Smith and Hubbard 1954, Bissell et al. 1955, Dietz et al. 1962). Thus it appears that a decline in bitterbrush abundance may have a major impact on the winter diet of the Entiat mule deer herd.

\section{Study Area and Specific Study Sites}

The Entiat mule deer herd inhabits that part of Washington from the Columbia River west to the Cascade Crest and from the Wenatchee River north to Lake Chelan. Most deer in this herd summer high in the Cascade Mountains and winter at lower elevtions along the Columbia River, a distance of approximately 70 $\mathrm{km}$. Their winter range extends south along the Columbia River from Lake Chelan to the Wenatchee River. The terrain is extremely rugged with sharp ridges and narrow valleys. Elevations range from $215 \mathrm{~m}$ along the Columbia River to $1200 \mathrm{~m}$ at the highest winter area.

Author is graduate research assistant, Wildlife Science Group, College of Forest Resources, University of Washington, Seattle, Washington 98195.

This study was conducted in cooperation with the U.S. Forest Service, Wenatchee National Forest and the Washington State Game Department. It was partially funded by the Wenatchec Sportsmen's Club. Thanks are extended to R.D. Taber, C.H. Driver, T.A. Hanley and R.M. Hansen for manuscript suggestions.

Manuscript received July 8, 1980.
Vegetation in the winter range varies from the Purshia tridentata-Agropyron spicatum steppe association to the Pinus ponderosa-Purshia tridentata association at higher elevations (Franklin and Dyrness 197.3). Common plants include: cheatgrass (Bromus tectorum). bluebunch wheatgrass(Agropyron spicatum), Sandberg bluegrass (Poa oldivae), buckwheat (Eriogonum spp.), arrowleaf balsamroot (Balsamorhiza sagittata), Oregongrape (Berberis repens), lupine (Lupinus spp.), bitterbrush, sagebrushes (Artemisia spp.), and ponderosa pine (Pinus ponderosa).

Mule deer food habits were studied in three sites, approximately $9 \mathrm{~km}$ apart, within the critical winter range (Fig. 1). (The critical winter range is defined as the wintering area at the lowest limits of the winter range on south-facing slopes.) The three sites differed in

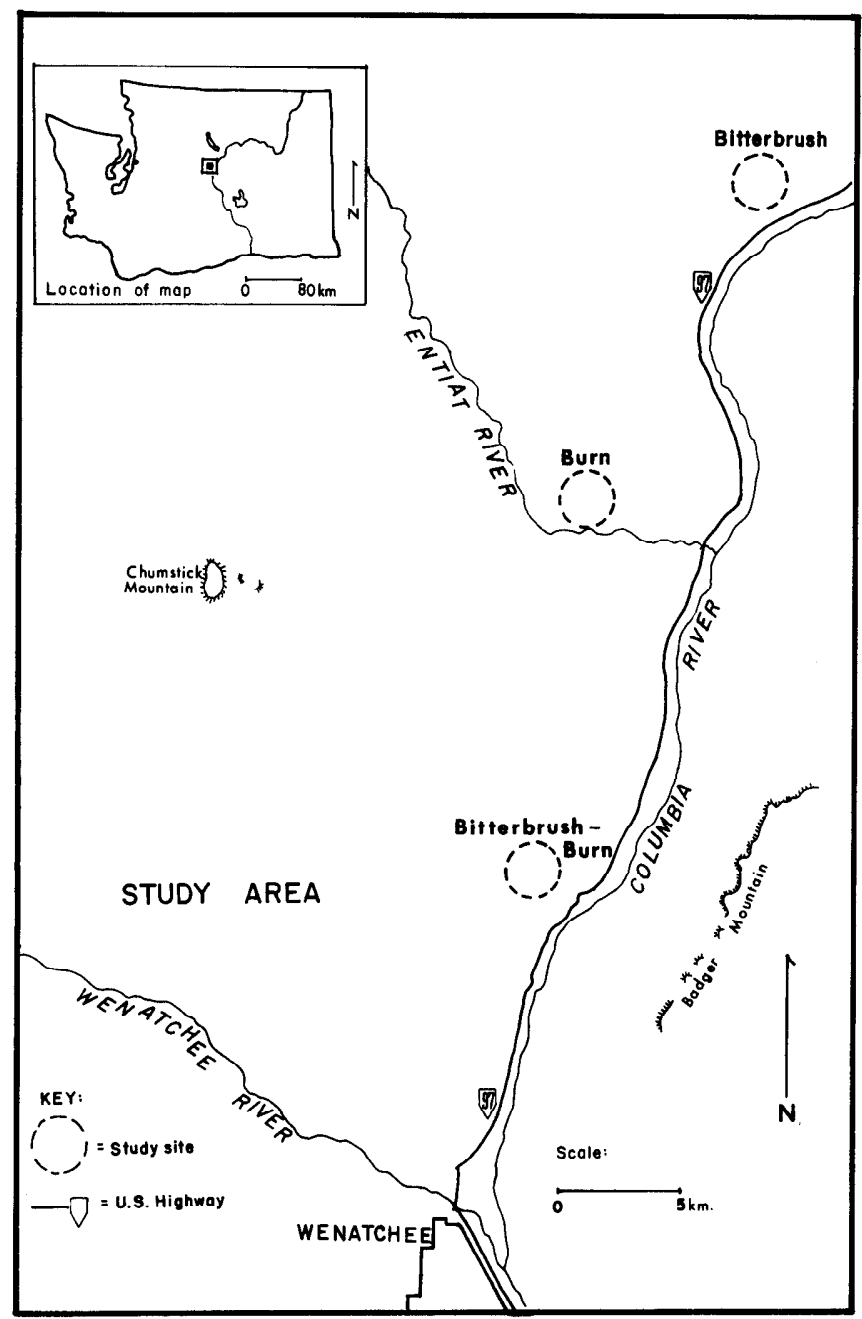

Fig. 1. Map showing the location of the three specific study sites. 
bitterbrush abundance with the bitterbrush site having a high density of bitterbrush plants throughout the area, the bitterbrushburn site having a high density of bitterbrush plants over one-half of its area while the other half had only a few remnant bitterbrush plants, and the burn site where only a few remnant bitterbrush plants remained after a fire in 1958 (Davis et al. 1970). The three sites were similar in aspect, elevation, and plant species composition. Mule deer movement was assumed to be negligible to nonexistant between areas due to the distance between sites, the ruggedness of the terrain and from reports by Gruell and Papez (1963) and Zeigler (1978) who found that mule deer move little while on the winter range.

The winter (December-February) mean monthly temperature and precipitation from Wenatchee, Washington, is $-1.1^{\circ} \mathrm{C}$ and 2.8 $\mathrm{cm}$ (U.S. Dept. of Commerce 1974, 1975, 1976). During the winter of 1974-1975 the average precipitation $(3.1 \mathrm{~cm})$ and temperature $\left(0.5^{\circ} \mathrm{C}\right)$ were normal, while the $1975-1976$ winter was mild with below normal precipitation $(2.4 \mathrm{~cm})$ and above normal temperature $\left(1.3^{\circ} \mathrm{C}\right)$.

\section{Methods}

The winter diet of the Entiat mule deer herd was determined by microscopic analyses of composited fecal samples. A composited fecal sample consisted of two pellets from each of at least 50 different pellet groups. Monthly fecal samples were collected from December-March 1974-1975 from the bitterbrush and bitterbrush-burn sites. In 1975-1976, samples were collected from December-March in the bitterbrush and burn sites and from January-March in the bitterbrush-burn site.

Plant fragments in feces were identified and quantified as described by Sparks and Malechek (1968). Twenty slides per sample with a total of 20 fields per slide were examined under a binocular microscope at $100 \times$ for recognizable plant fragments. Studies by Todd and Hansen (1973), Hansen et al. (1973), Anthony and Smith (1974), and Dearden et al. (1975) report that the percentage of the classified plant fragments appears to approximate the percentage relative dry weights of food categories in the diet.

Bitterbrush availability was measured from November-March during the 1975-1976 winter in the bitterbrush site. Ten randomly selected plants were marked on south-facing slopes. Fifty current leaders on each plant, less than $2 \mathrm{~m}$ from the ground, were measured each month and their average length determined. By multiplying the percent used each month by the amount available from the preceeding month a monthly bitterbrush availability was calculated.

Bitterbrush preference was measured throughout the winter of 1975-1976 in the bitterbrush site by a selectivity index (Ivlev 1961). The formula for the index is:

$$
\frac{r_{\mathrm{i}}-p_{\mathrm{i}}}{r_{\mathrm{i}}+p_{\mathrm{i}}}=E
$$

where $r_{\mathrm{i}}$ is the proportion of item in the diet, $p_{\mathrm{i}}$ equals the proportion of the item in the environment and $E$ is the selectivity index. Positively selected species are sought out in the environment, while negatively selected species are not.

\section{Results and Discussion}

The bulk of the mule deer winter diet in the study area was made up of four plants-bitterbrush, buckwheat, balsamroot, and lupine-though some 23 other species were eaten in smaller amounts. These four plants made up $90 \%$ of the diet in the bitterbrush site, $87 \%$ in the bitterbrush-burn site, and $93 \%$ in the burn site. Use of these four plants varied with time and between sites.

In the bitterbrush site in 1974-1975 bitterbrush use was heavy, averaging $70 \%$ until March when it dropped to $17 \%$. As bitterbrush use declined the use of buckwheat increased to $48 \%$ in March. In 1975-1976 bitterbrush use was heavy throughout the winter though use dropped slightly from an average of $86 \%$ for the first three
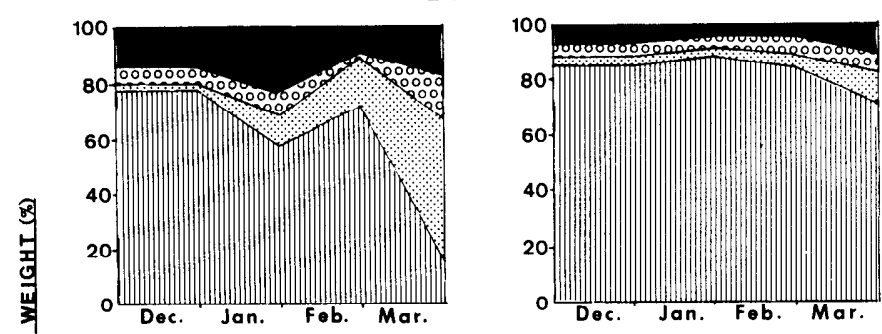

BITTERBRUSH-BURN
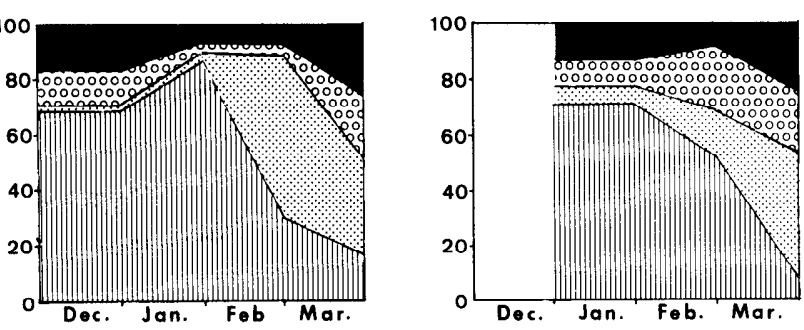

BURN
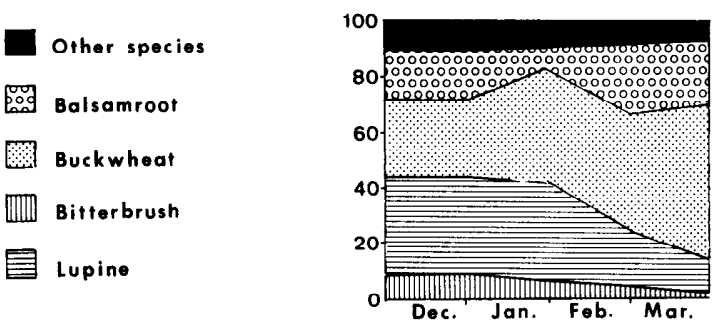

Fig. 2. Major trends of use of the most heavily utilized plant species in the bitterbrush, bitterbrush-burn and burn sites during the winters of 19741975 and 1975-1976.

months to $69 \%$ in March. As bitterbrush use declined, buckwheat use increased from an a verage of $4 \%$ for the first 3 mont hs to $12 \%$ in March. Balsamroot use averaged $8 \%$ for $1974-1975$ and $6 \%$ for 1975-1976.

In the bitterbrush-burn site in 1974-1975, bitterbrush use averaged $77 \%$ for December and January. Then use dropped to $29 \%$ and $16 \%$ for February and March, respectively. As bitterbrush use declined the use of buckwheat increased from an average of $2 \%$ in December and January to an average of $48 \%$ for February and March. In 1975-1976 bitterbrush use was $70 \%$ in January, 52\% in February and $9 \%$ in March. For the same period, buckwheat use was $7 \%, 16 \%$, and $44 \%$. Balsamroot use averaged $10 \%$ for 1974-1975 and $22 \%$ for $1975-1976$.

In the burn site the heaviest eaten plants were buck wheat, $42 \%$, and lupine, $26 \%$, with buckwheat use increasing and lupine use decreasing from the beginning to end of winter. Bitterbrush use dropped from $9.4 \%$ in December to $1 \%$ in March. Balsamroot use averaged $19 \%$ for the entire winter with little monthly variation.

The most obvious trend during the study was the decline in bitterbrush use between sites and as winter progressed within sites. There were two probable reasons for a decline in bitterbrush use: decreased preference or decreased availability.

A study of bitterbrush preference in the bitterbrush site in 1975-1976 showed that annual bitterbrush leaders were highly preferred by mule deer. Bitterbrush selectivity indexes were: +0.54 , $+0.57,+0.59$, and +0.59 , for December, January, February, and March, respectively. The high positive selectivity index values indicate that bitterbrush was highly sought out in the environment by mule deer. Therefore, decreased use of annual bitterbrush leaders was not related to declining preference.

Instead, decreased use of bitterbrush and the subsequent increase in buckwheat use appeared to be directly related to bitter- 
brush availability. Evidence for this was that bitterbrush made up $69 \%$ of the total diet in the bitterbrush site, $47 \%$ in the bitterbrushburn site and only $6 \%$ in the burn site. Also, bitterbrush use declined in all areas as winter progressed, which suggests that its availability also declined since its preference did not. Leach (1956), Wilkins (1957), and Richens (1967) also reported that declines in bitterbrush use were caused by a decline in its availability.

Changes in the diet of the Entiat mule deer herd due to changes in bitterbrush abundance were significant. Since bitterbrush is high in nutritional quality it could be assumed that declines in bitterbrush would adversely affect the winter survival of the deer herd. This would be the case if buckwheat and other forage species did not adequately replace it in the herd's diet. However, mule deer do successfully winter on ranges without bitterbrush (Burrell 1977) which suggests that buckwheat and other forage species do adequately replace bitterbrush in the herd's diet.

\section{Literature Cited}

Anthony, R.G., and N.S. Smith. 1974. Comparison of rumen and fecal analysis to describe deer diets. J. Wildl. Manage. 38:535-540.

Bissell, H., B. Harris, H. Strong, and F. James. 1955. The digestibility of certain natural and artificial food eaten by deer in California. California Fish and Game. 41:57-58.

Burrell, G.C. 1977. Bitterbrush (Purshia tridentata) in the winter ecology of the Entiat mule deer herd. MS Thesis, Univ. of Washington, Seattle.

Cliff, E.P. 1939. Relationship between elk and mule deer in the Blue Mountains of Oregon. Trans. N. Am. Wildl. Conf. 4:560-569.

Davis, J.A., R.R. Randall, and J.R. Patterson. 1970. Biological unit plan for the Entiat deer herd. U.S. Forest Serv., Wenatchee Natl. Forest.

Dearden, B.L., R.E. Pegau, and R.M. Hansen. 1975. Precision of microhistological estimates of ruminant food habits. J. Wildl. Manage. 39:402407.

Dietz, D.R., R.H. Udall, and L.E. Yeager. 1962. Chemical composition and digestibility by mule deer of selected forage species, Cache La Poudre Range, Colorado. Tech. Pub., Colorado Game and Fish Dep. No. 14.
Edwards, O.T. 1942. Survey of winter deer range, Malheur National Forest, Oregon. J. Wildl. Manage. 6:210-221.

Franklin, J.F., and C.T. Dyreness. 1973. Natural vegetation of Oregon and Washington. U.S. Dep. Agr. Forest Serv., Gen. Tech. Rep. PNW-8.

Gjertson, J. 1973. Annual progress report on the cooperative Chelan County mule deer study. U.S. Forest Serv., Wenatchee Natl. Forest.

Gruell, G.E., and N.J. Papez. 1963. Movements of mule deer in northeastern Nevada. J. of Wildl. Manage. 27:414-422.

Hansen, R.M., D.C. Peden, and R.W. Rice. 1973. Discerned fragments in feces indicates diet overlap. J. Range Manage. 26:103-105.

Hoskins, L.W., and P.D. Dalke. 1955. Winter browse on the Pocatello big game range in southeastern Idaho. J. Wildl. Manage. 19:215-225.

Ivlev, V.S. 1962. Experimental feeding ecology of fishes. Yale Univ. Press, New Haven, Conn.

Leach, H.R. 1956. Food habits of the Great Basin deer herds of California. California Fish and Game. 42:241-293.

Richens, V.B. 1967. Characteristics of mule deer herds and their range in northeastern Utah. J. Wildl. Manage. 31:651-666.

Smith, A.D., and D.M. Gaufin. 1950. The use of movable paddocks in the study of forage preferences of mule deer and livestock. Trans. N. Amer. Wildl. Conf. 15:512-517.

Smith, A.D., and R.L. Hubbard. 1954. Preference ratings for winter deer forages from northern Utah ranges based on browsing time and forage consumed. J. Range Manage. 7:262-265.

Sparks, D.R., and J.C. Malechek. 1968. Estimating percentage dry weights in diets using a microscopic technique. J. Range. Manage. 21:264-265.

Todd, J.W., and R.M. Hansen. 1973. Plant fragments in the feces of bighorns as indicators of food habits. J. Wildl. Manage. 37:363-366.

United States Department of Commerce. 1974, 1975, and 1976. Local climatological data. Wenatchee, Washington. Natl. Oceanic and Atmospheric Admin., Environ. Data Serv.

Wilkins, B.T. 1957. Range use, food habits, and agricultural relationships of mule deer, Bridger Mountains, Montana. J. Wildl. Manage. 21:159169.

Zeigler, D.L. 1978. The Okanogan mule deer. Wash. Dept. of Game. Bio. Bull. No. 15. Olympia, Washington.

\section{THE DATE ON YOUR JOURNAL}

As you may have noticed, you received the August issue of Rangelands before you received the July issue of the Journal of Range Management. This condition exists because the Journal has grown from a normal 352 pages by the end of July to 544 with this issue. The staff has remained the same. We are deeply grateful for the extra pages to reduce the backlog this year, but this does mean that issues will fall behind schedule until we return to normal workload. Since Rangelands carries Society announcements and registration forms that have deadlines, it is crucial that that publication reach readers on schedule. When you receive the October Rangelands, do not feel that your September Journal has been lost in mailing. All 136 pages of it will come. Thank you for your patience. 